\title{
Biodiesel production from butter factory effluent
}

\author{
Corneels Schabort ${ }^{\star}$, Hennie Visser, Roelf Venter and Sanette Marx \\ Energy Systems, School of Chemical and Mineral Engineering, North-West University, Hoffman Street, \\ Potchefstroom, South Africa.
}

Accepted 3 February, 2014

\begin{abstract}
The increase in energy demand coupled with the depletion of fossil fuels has increased the need for renewable and sustainable energy sources. Butter waste effluent was identified as a possible feedstock for biodiesel. The effects of the temperature, alcohol to oil molar ratio, catalyst concentration and the reaction time were investigated to determine the optimal reaction conditions of the transesterification reaction. The optimal reaction conditions according to the results were $50^{\circ} \mathrm{C}, 6: 1$ alcohol to oil molar ratio, 1.0 to $1.2 \mathrm{wt} \%$ catalyst loads and a reaction time of 60 to $90 \mathrm{~min}$. Different methods of purification were investigated in an attempt to decrease waste of a biodiesel plant, including the dry washing agents, Magnesol ${ }^{\circledR}$ D-SOL ${ }^{\mathrm{TM}}$ and Purolite ${ }^{\circledR}$ PD-206. The Magnesol ${ }^{\circledR}$ D-SOL ${ }^{\mathrm{TM}}$ was found to be the optimum method for lowering the water content and the acid value of the fuel. The biodiesel was tested according to the SANS 1935:2011 standard and did not meet the requirements of the standard with regard to flash point, sulphur content, carbon residue, oxidation stability, free glycerol, total glycerol and cold filter plugging point. In order for the biodiesel to be suitable for commercial use, it should be blended with mineral diesel.
\end{abstract}

Key words: Transesterification, butter waste, biodiesel purification, reaction kinetics.

\section{INTRODUCTION}

With the ever-increasing world population, there is an increasing demand for energy (BP, 2012; United Nations, 2011). The increasing energy demand is putting a strain on the fossil fuel reserves and therefore increasing fuel prices. The need for sustainable, renewable fuel sources cannot be emphasised enough. Biofuels have been investigated as an alternative to fossil fuels. The feedstock for biofuels has changed during the last years from edible to non-edible, and finally to waste sources. The change was driven by the food versus fuel debate, that is, the unethical use of food for fuel (Ewing and Msangi, 2009). The use of waste fats and oils for biodiesel has been the focus of recent research. The waste from a butter factory in Frankfort (Free State Province, South Africa) was identified as a possible feedstock for biodiesel production. The waste is produced during cleaning processes. The effluent (a mixture of oil and water) from the factory is collected in a settling pit. The water is separated from the oil and discarded into the municipal sewerage. The oil is removed and stored. Fines are issued by the municipality for dumping fat in the sewerage system in an effort to reduce the environmental impact of the industries in the area. Pereira et al. (2003) observed toxic conditions in sediments which were polluted with linseed and sunflower oil. The waste should thus be disposed of in an environmentally friendly manner and this increases the production cost.

The fatty waste can be used to produce biodiesel, which can in turn be used to fuel machinery at the factory. This will decrease the overall production cost of the factory by decreasing disposal costs and operating costs. The aim of the study was to develop a complete biodiesel production process from a butter waste that will produce a biodiesel that conforms to the SANS1935:2011 
Table 1. Characteristics of butter waste.

\begin{tabular}{lc}
\hline Property & Value \\
\hline Water content (wt\%) & 0.17 \\
FFA content (wt\%) & 0.2 \\
Density $\left(\mathrm{kg} / \mathrm{m}^{3}\right)$ & 914 \\
Viscosity at $40^{\circ} \mathrm{C}\left(\mathrm{mm}^{2} / \mathrm{s}\right)$ & 46.9 \\
\hline
\end{tabular}

standards.

\section{MATERIALS AND METHODS}

The waste oil was dried to reduce the water content to below 0.1 $w t \%$. The dried oil was stored in $25-L$ containers for ease of transport and handling. There are a few processes for biodiesel production. The most commonly used process is the alkalicatalysed transesterification reaction, requiring a feedstock with a water content of less than $0.1 \mathrm{wt} \%$ in order to avoid undesirable side reactions (Cvengros and Cvengrosova, 2004). A feedstock with a free fatty acid (FFA) content of less than $2 \mathrm{wt} \%$ (Hayyan et al., 2011), 3 wt\% (Meher et al., 2006) and 5 wt\% (Van Gerpen, 2005) has been reported to give the best yields. Thus, a feedstock with less than 2 wt\% FFA will be acceptable for biodiesel production. The characteristics of the oil are shown in Table 1.

\section{Biodiesel production}

The heated and well mixed oil $(300 \mathrm{~g})$ was transferred to a $2 \mathrm{~L}$ three-neck round-bottom reaction flask. The flask was fitted with a condenser, thermometer and a sampling tube. The flask was heated by means of a heating mantle and the agitation was done with a magnetic stirrer. The stirring speed was kept constant for all reactions at $375 \mathrm{rpm}$. The samples were extracted into a centrifuge tube by the sampling tube. A hydrochloric acid solution was added to the sample to deactivate the catalyst and stop the reaction. The sample was then centrifuged at 1,200 rpm for $5 \mathrm{~min}$ and the bottom water rich layer was removed. The process was repeated four more times with water at $60^{\circ} \mathrm{C}$. The sample was then dried in an oven at $105^{\circ} \mathrm{C}$ for $2 \mathrm{~h}$ before analysis. The effect of the alcohol to oil molar ratio was calculated for ratios $3: 1,4: 1,5: 1,6: 1,7: 1$ and 8:1. The temperature was varied from 45 to $65^{\circ} \mathrm{C}$ with $5^{\circ} \mathrm{C}$ increments and the potassium hydroxide loads used in this experiment were 0.8 , 1.0 and $1.2 \mathrm{wt} \%$.

\section{Purification of biodiesel}

The purification step was done with water, in order to remove the unreacted methanol and remaining catalyst from the biodiesel. This method increases the effluent of a biodiesel plant and increases the production costs since the effluent should be treated before discarding it. The water washing step is also followed by a drying step which can affect the quality of the biodiesel. The use of resins was investigated to eliminate the water washing purification step. The two resins used in this study were Magnesol ${ }^{\circledR} \mathrm{D}-\mathrm{SOL}^{\mathrm{TM}}$ and Purolite ${ }^{\circledR}$ PD-206. These resins have been proven to reduce the water content, acid number, soap content, methanol content and potassium content of biodiesel (Manique et al., 2012; Faccini et al., 2011). The untreated and unwashed biodiesel was heated to $65^{\circ} \mathrm{C}$ before the resins were added. This is to remove the excess of unreacted methanol. The resins were then added and stirred for 30 min at $65^{\circ} \mathrm{C}$. Samples were taken every $10 \mathrm{~min}$ and analysed. The experiments were carried out with resin loads of $0.5,1.0,1.5$ and $2.0 \mathrm{wt} \%$. The resins have also been shown to remove impurities like mono-, di- and triglycerides and free glycerol (Berrios and Skelton, 2008).

\section{Analytical methods}

The ester content of the biodiesel was determined with gas chromatography (GC). The filter samples were injected into an Agilent $7890 \mathrm{~A}$. The Agilent HP-88, $100 \mathrm{~m}(0.25 \mathrm{~mm}$, internal diameter and $0.2 \mu \mathrm{m}$ film thickness) column was used to separate the esters. The GC was set up according to the following conditions: helium was used as carrier gas with a linear velocity of $35 \mathrm{~cm} / \mathrm{s} ; 1 \mu \mathrm{L}$ samples were injected into the column. The temperature profile was as follows: $250^{\circ} \mathrm{C}$ inlet temperature; $100^{\circ} \mathrm{C}$ for $5 \mathrm{~min}$; ramp at $10^{\circ} \mathrm{C} / \mathrm{min}$ up to $120^{\circ} \mathrm{C}$ and hold for $1 \mathrm{~min}$; ramp at $10^{\circ} \mathrm{C} / \mathrm{min}$ up to $175^{\circ} \mathrm{C}$ and hold for $10 \mathrm{~min}$; ramp at $5^{\circ} \mathrm{C} / \mathrm{min}$ up to $210^{\circ} \mathrm{C}$ and hold for $5 \mathrm{~min}$; ramp at $5^{\circ} \mathrm{C} / \mathrm{min}$ up to $230^{\circ} \mathrm{C}$ and hold for $5 \mathrm{~min}$. A flame ionisation detector (FID) was used at $350^{\circ} \mathrm{C}$.

\section{RESULTS AND DISCUSSION}

The purified product consists of $96.16 \pm 4$ wt\% esters as analysed by GC and a reaction yield of 87 wt\% was achieved. The effects of temperature, alcohol to oil molar ratio, catalyst load and reaction time were determined.

\section{Temperature}

The effect of temperature on the ester content can be seen in Figure 1. The reaction temperatures used were $45,50,55,60$ and $65^{\circ} \mathrm{C}$. There is an increase in ester content with an increase in temperature up to $50^{\circ} \mathrm{C}$. A further increase in temperature decreases the ester content. This is due to the boiling point of methanol. An increase in temperature above the boiling point will result in more methanol evaporating. This reduces the alcohol to oil molar ratio in the reaction mixture and thus favours the reverse reaction.

\section{Alcohol to oil molar ratio}

The effect of alcohol to oil molar ratio on the reaction yield is shown in Figure 2. There is an increase in ester content with an increase in alcohol to oil molar ratio. This increase is clear up to a ratio of 6:1. Further increase in methanol has no significant change in ester content. This is seen for varying temperatures and catalyst loads. A ratio of $6: 1$ is double the stoichiometric ratio. An alcohol to oil molar ratio of $6: 1$ is needed to shift the reaction towards the right for the duration of the reaction and to achieve the highest conversion.

\section{Catalyst load}

The effect of catalyst load on the ester content can be 


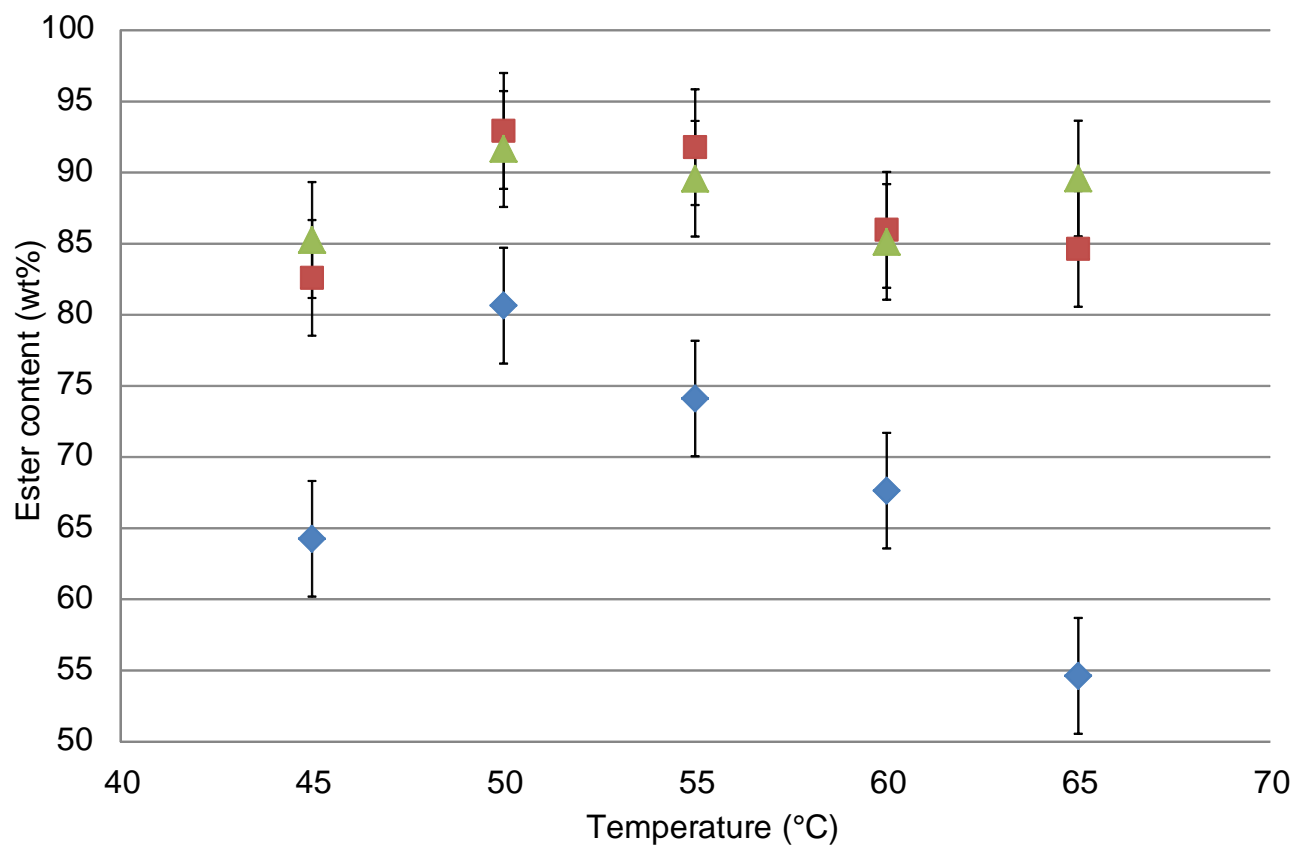

Figure 1. Chemical analyses of extracted water; influence of reaction temperature on ester content with a catalyst load of $1.2 \mathrm{wt} \%$, a reaction time of $120 \mathrm{~min}$, and alcohol to oil molar ratios of $3: 1$ $(\diamond), 6: 1(\mathbf{\square})$ and 8:1 (४) .

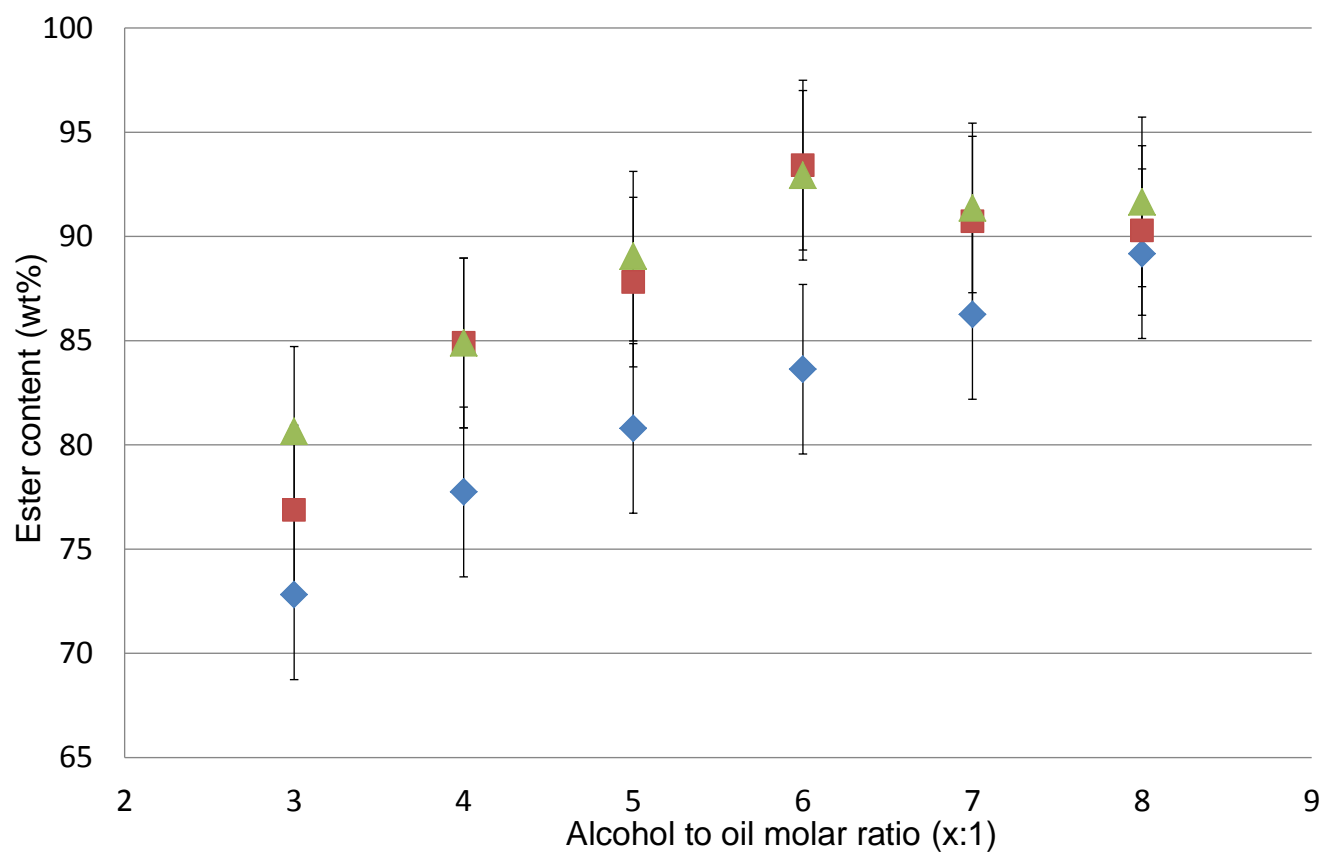

Figure 2. Influence of alcohol to oil molar ratio on ester content with a reaction time of $120 \mathrm{~min}$, a reaction temperature of $50^{\circ} \mathrm{C}$ and catalyst loads of $0.8 \mathrm{wt} \%(\bullet), 1 \mathrm{wt} \%(\boldsymbol{\nabla})$ and $1.2 \mathrm{wt} \%(\mathbf{\Delta})$.

seen in Figure 3. There is an increase in ester content with an increase in catalyst concentration at low temperatures $\left(45^{\circ} \mathrm{C}\right)$. The effect of increasing catalyst load is, however, very limited at higher temperatures $\left(>50^{\circ} \mathrm{C}\right)$. The catalyst facilitates the forward reaction to reach equilibrium in a shorter amount of time. The equili- 


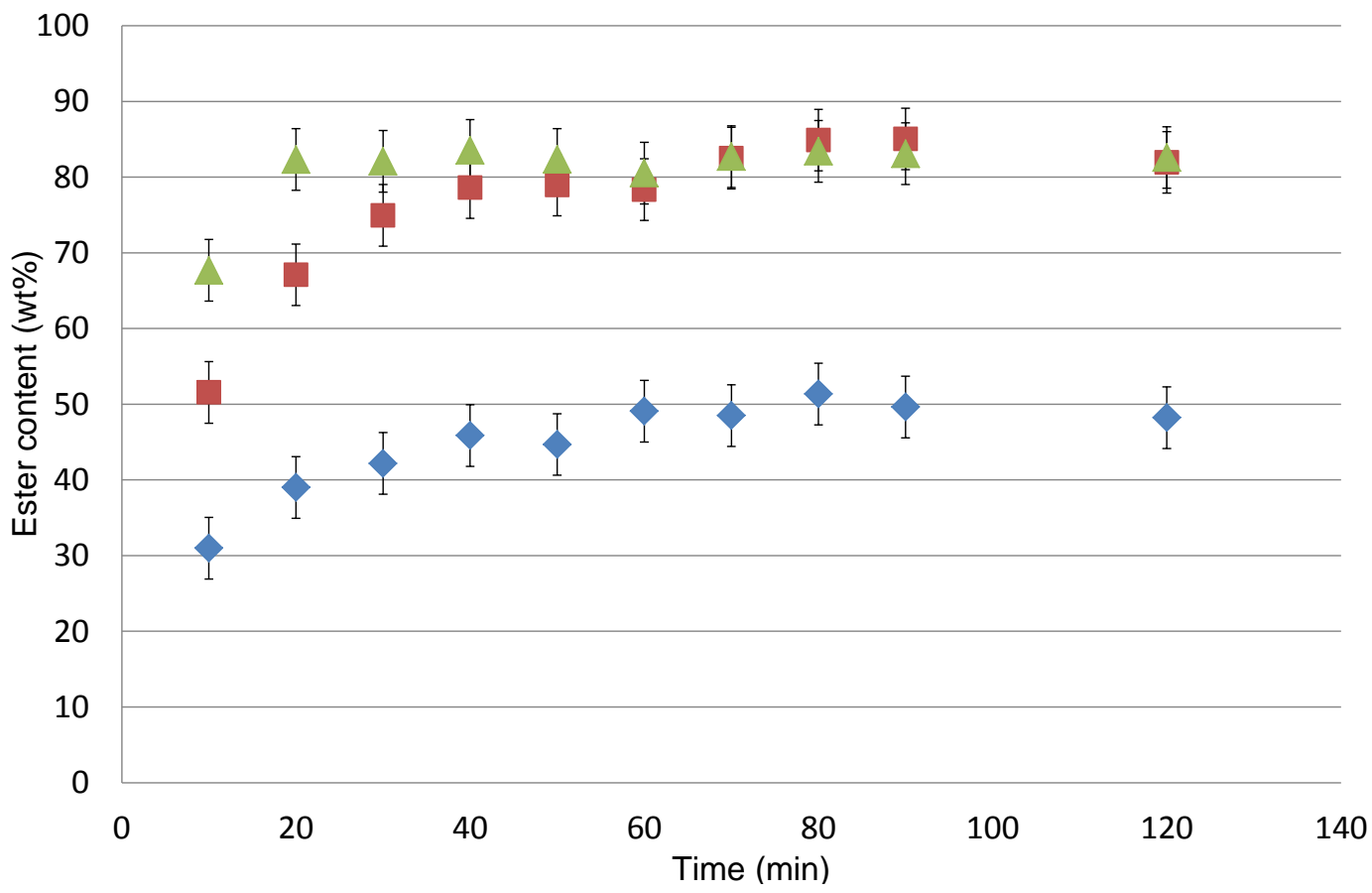

Figure 3. Influence of catalyst load on ester content with a reaction temperature of $45^{\circ} \mathrm{C}$, an alcohol to oil molar ratio of $6: 1$ and catalyst loads of $0.8 \mathrm{wt} \%(\bullet), 1 \mathrm{wt} \%(\boldsymbol{\square})$ and $1.2 \mathrm{wt} \%(\mathbf{\Delta})$.

brium of the 0.8 and $1.0 \mathrm{wt} \%$ reactions is reached after $40 \mathrm{~min}$, but this is lowered to $20 \mathrm{~min}$ with a catalyst load of $1.2 \mathrm{wt} \%$. An increase in temperature increases the reactivity of the molecules. The catalyst is used to lower the activation energy. An increase in catalyst load will not affect the ester content at higher temperatures since the activation energy needed is already supplied by the heat source. The optimal reaction conditions for biodiesel production with the alkali-catalysed transesterification reaction are a reaction temperature of $50^{\circ} \mathrm{C}$, an alcohol to oil molar ratio of $6: 1$ and a catalyst load of 1.0 to $1.2 \mathrm{wt} \%$. A reaction time of 60 to $90 \mathrm{~min}$ is needed to reach equilibrium and maximum conversion.

\section{Purification}

The effect of Magnesol ${ }^{\circledR}$ D-SOL ${ }^{\mathrm{TM}}$ can be seen in Figure 4. The initial water content was $1,700 \mathrm{ppm}$. The water content of the biodiesel is lowered with an increase of time. The efficiency of the Magnesol ${ }^{\circledR} \mathrm{D}-\mathrm{SOL}^{\mathrm{TM}}$ lowers as more is added to the system. This is consistent with literature (Faccini et al., 2011). The acid value of the biodiesel is also lowered by the Magnesol ${ }^{\circledR} \mathrm{D}-\mathrm{SOL}^{\mathrm{TM}}$. The acid value is lowered from 2.78 to $0.13 \mathrm{mg} \mathrm{KOH} / \mathrm{g}$ with a $0.5 \mathrm{wt} \%$ load of the resin, at a reaction time of $30 \mathrm{~min}$. The ester content of the biodiesel was increased from 86.74 to 96.98 wt $\%$ with a load of 0.5 wt $\%$ and reaction time of $20 \mathrm{~min}$. The optimum load and reaction time for biodiesel purification with Magnesol ${ }^{\circledR} \mathrm{D}-\mathrm{SOL}^{\mathrm{TM}}$ is $0.5 \mathrm{wt} \%$ with a reaction time of $20 \mathrm{~min}$. The effect of Purolite ${ }^{\circledR} \mathrm{PD}$ 206 as purification agent is seen in Figure 5. A decrease in water content is observed with an increase in Purolite ${ }^{\circledR}$ PD-206 for 1.0, 1.5 and $2.0 \mathrm{wt} \%$. There is no significant change in water content for a load of $0.5 \mathrm{wt} \%$. The water content increases with an increase in load. This is not consistent with literature (Faccini et al., 2011). The acid value of the biodiesel decreases with an increase in load. However, a load of $2.0 \mathrm{wt} \%$ is not enough to lower the acid value to the desired value of the SANS 1935:2011 standard. The ester content of the biodiesel increases with an increase in Purolite $\AA$ PD-206. The ester content is increased from 86.74 to 98.8 wt\% with a load of 0.5 wt $\%$ and a reaction time of $20 \mathrm{~min}$.

Magnesol ${ }^{\circledR} \mathrm{D}-\mathrm{SOL} \mathrm{L}^{\mathrm{TM}}$ is the better washing agent since it brings all of the evaluated parameters within the specified range of SANS 1935:2011. The SANS 1935:2011 results of the biodiesel are displayed in Table 2. The parameters that do not meet the requirements (indicated in bold) will be discussed as follows:

\section{Flashpoint}

The flash point can be described as the lowest temperature where enough combustible vapour is emitted to create a flame (Carrero and Perez, 2012). The average flash point of biodiesel is above $150^{\circ} \mathrm{C}$ (Boog et al., 2011; Kumar et al., 2013). The flash point is usually lowered by unreacted methanol and can lower the flash 


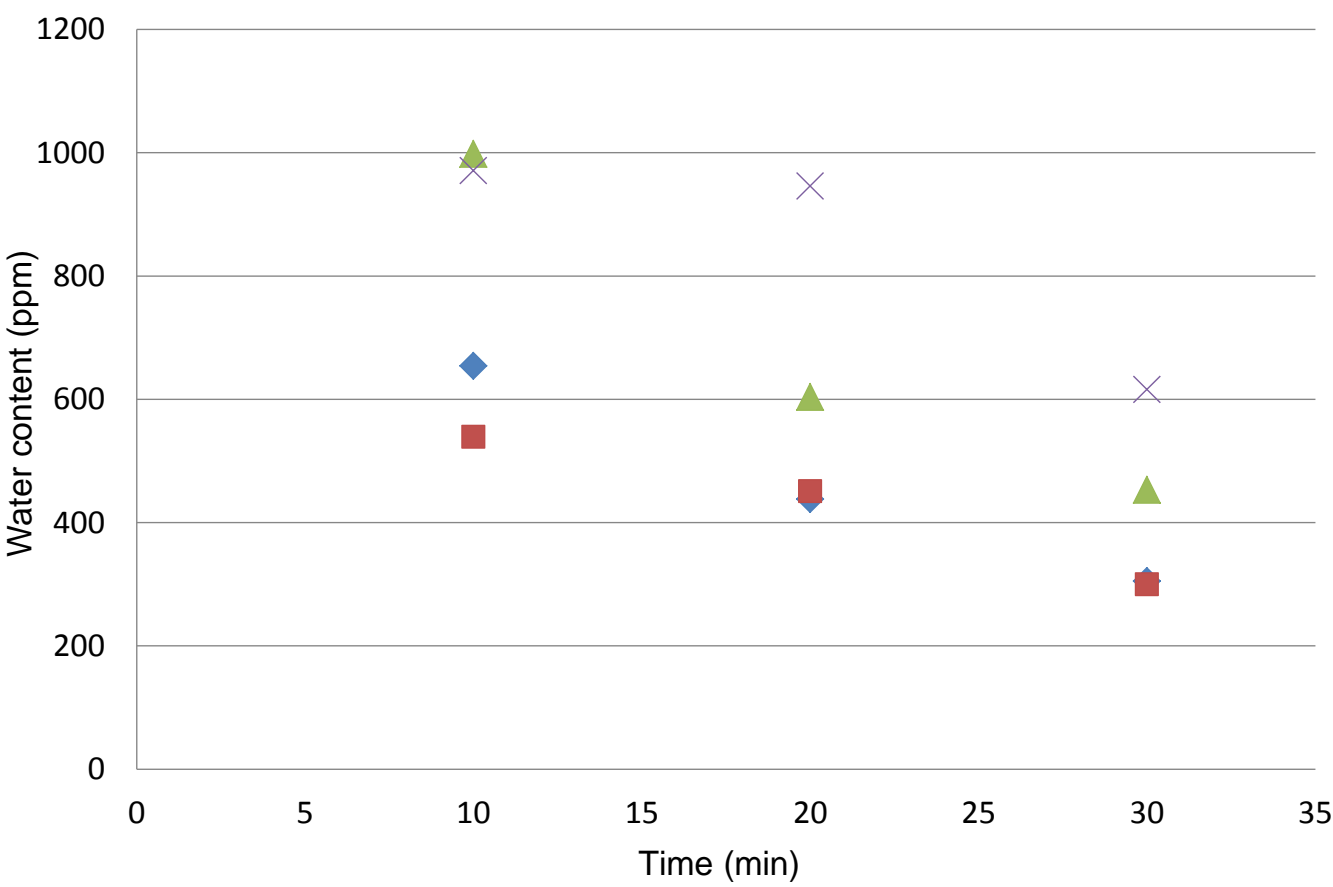

Figure 4. The effect of Magnesol ${ }^{\circledR} \mathrm{D}-\mathrm{SOL}^{\mathrm{TM}}$ on the water content of biodiesel $(\bullet 0.5 \mathrm{wt} \%$, 1.0 wt $\%, \triangle 1.5 \mathrm{wt} \%, \times 2.0 \mathrm{wt} \%)$.

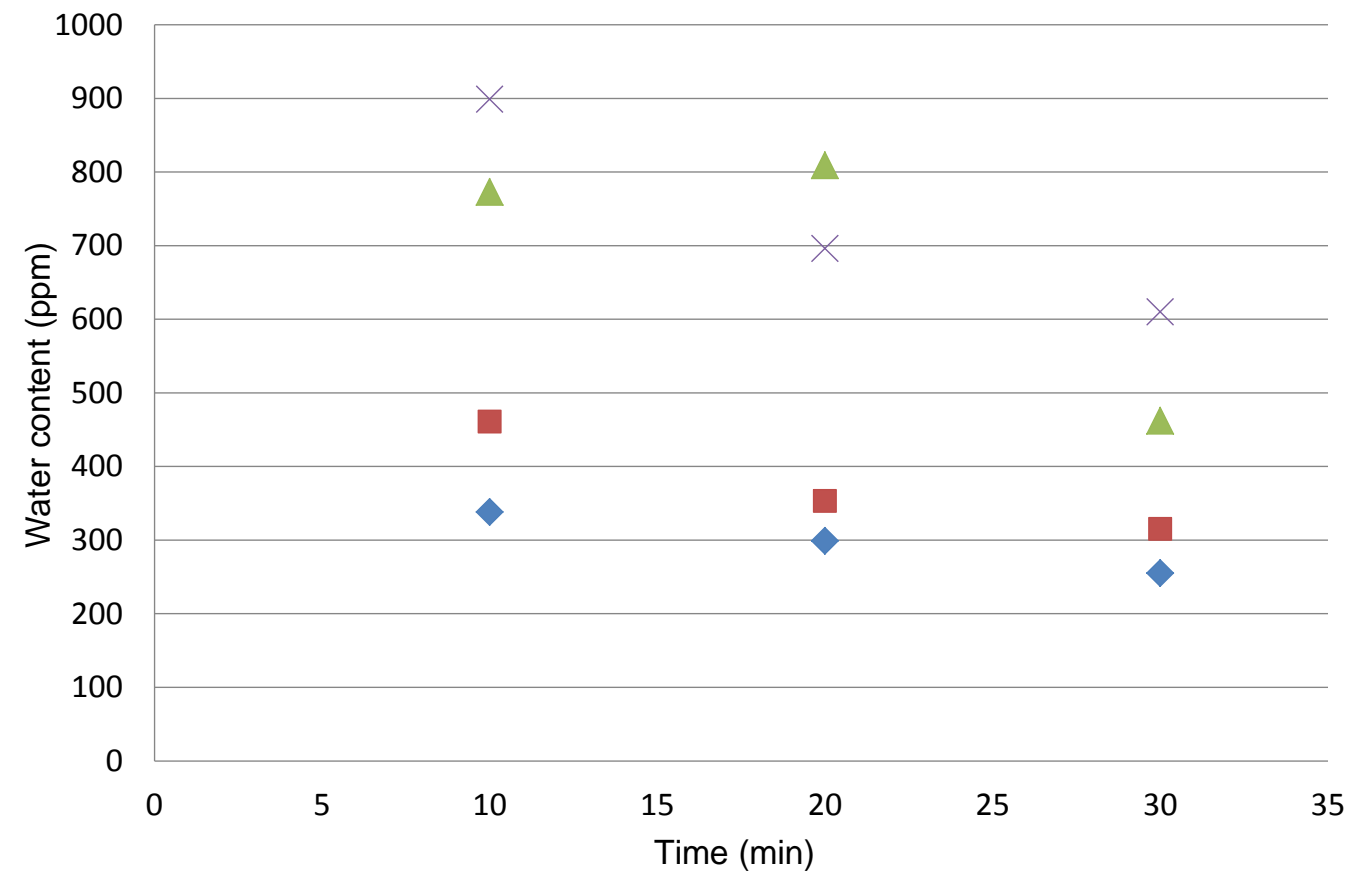

Figure 5. The effect of Purolite ${ }^{\circledR}$ PD-206 on the water content of biodiesel $(\diamond 0.5$ wt $\%$, 1.0 wt\%, $\Delta$ $1.5 \mathrm{wt} \%, 2.0 \mathrm{wt} \%$, SANS 1935:2011 maximum limit).

point from 178 to $105^{\circ} \mathrm{C}$ with the addition of $0.123 \mathrm{wt} \%$ methanol (Boog et al., 2011). No methanol could be detected by means of GC analysis in the biodiesel. The biodiesel produced from the butter waste has a broad range of esters. The biodiesel contains small amounts of short chain esters. The flash points of these esters are 
Table 2. The SANS 1935:2011 parameters of biodiesel produced from butter waste.

\begin{tabular}{|c|c|c|}
\hline Property & SANS 1935:2011 & Result \\
\hline Ester content (wt\%, min) & 96.5 & 96.16 \\
\hline Density at $15^{\circ} \mathrm{C}\left(\mathrm{kg} / \mathrm{m}^{3}\right)$ & $860-900$ & 877.4 \\
\hline Kinematic viscosity at $40^{\circ} \mathrm{C}\left(\mathrm{mm}^{2} / \mathrm{s}\right)$ & $3.5-5.0$ & 4.2 \\
\hline Flash point $\left({ }^{\circ} \mathrm{C}, \mathrm{min}\right)$ & 101 & 68 \\
\hline Sulphur content (mg/kg, max) & 10 & 50 \\
\hline Carbon residue (on $10 \%$ distillation residue) (wt $\%$, max) & 0.3 & 1.3 \\
\hline Cetane number (min) & 51.0 & 68.8 \\
\hline Sulphated ash content (wt\%, max) & 0.02 & 0.001 \\
\hline Water content $(\mathrm{mg} / \mathrm{kg}, \mathrm{max})$ & 500 & 315 \\
\hline Total contamination (mg/kg, max) & 24 & 5 \\
\hline Copper strip corrosion $\left(3 \mathrm{~h}\right.$ at $\left.50^{\circ} \mathrm{C}\right)$ (rating, min) & Class 1 & Class 1 \\
\hline Oxidation stability, at $110^{\circ} \mathrm{C}(\mathrm{h}, \mathrm{min})$ & 6 & 0.8 \\
\hline Acid value (mg KOH/g, max) & 0.5 & 0.078 \\
\hline lodine value, $\mathrm{g}$ of iodine $/ 100 \mathrm{~g}$ of FAME (max) & 140 & 45 \\
\hline Linolenic acid methyl ester (wt\%, max) & 12 & 1.328 \\
\hline Polyunsaturated ( $>=4$ double bonds) methyl ester (wt $\%, \max$ ) & 1 & $\mathrm{~N} / \mathrm{D}$ \\
\hline Methanol content ( $w t \%, \max )$ & 0.2 & $N / D$ \\
\hline Monoglyceride content (wt\%, max) & 0.8 & $\mathrm{~N} / \mathrm{A}$ \\
\hline Diglyceride content (wt\%, max) & 0.2 & $N / A$ \\
\hline Triglyceride content (wt\%, max) & 0.2 & $\mathrm{~N} / \mathrm{A}$ \\
\hline Free glycerol (wt\%, max) & 0.02 & 0.04 \\
\hline Total glycerol (wt\%, max) & 0.25 & 0.27 \\
\hline Group 1 metals (total of $\mathrm{Na}$ and $\mathrm{K}$ ) (mg/kg, max) & 5 & 0 \\
\hline Group 2 metals (total of $\mathrm{Ca}$ and $\mathrm{Mg}$ ) (mg/kg, max) & 5 & 2 \\
\hline Phosphorous content (mg/kg, max) & 4 & 1 \\
\hline \multicolumn{3}{|l|}{ Cold filter plugging point } \\
\hline Winter $\left({ }^{\circ} \mathrm{C}, \mathrm{min}\right)$ & -4 & +8 \\
\hline Summer $\left({ }^{\circ} \mathrm{C}, \mathrm{min}\right)$ & +3 & \\
\hline
\end{tabular}

well below the standard and are therefore responsible for the undesired result. A solution to increase the low flash point is to remove the short chain esters by distillation or to blend with mineral diesel. A B10 and B20 blend of biodiesel in diesel gave a flash point of 52 and $55^{\circ} \mathrm{C}$, respectively. This is lower than specified by SANS 1935:2011 (SABS, 2011) but the flash point of the B20 blend is above the minimum specified by the SANS 342:2006 standard for diesel (SABS, 2006).

\section{Sulphur content}

The sulphur content of the biodiesel is above the maximum level, but is within the range of SANS 342:2006. Thus, a blend of the biodiesel with a low sulphur content $(50 \mathrm{ppm})$ diesel will be within specification.

This might be a problem for future specification for biodiesel since the standard for sulphur content will decrease to 10 ppm by 2017 in South Africa.

\section{Carbon residue}

The carbon residue is an indication of the amount of impurities in the biodiesel that will be left behind after combustion of the fuel. The impurities may cause engine failures due to blockage of the fuel injectors (Carrero and Perez, 2012). The biodiesel can be filtered or blended with mineral diesel to lower the carbon residue.

\section{Oxidation stability}

The oxidation stability is an indication of the storage conditions needed for the biodiesel. The oxidation stability is measured by heating the biodiesel to $110^{\circ} \mathrm{C}$ and aerating the sample. The air is then dissolved in water and the change in conductivity is measured. The oxidation stability induction period is determined when a sudden increase in conductivity is measured. Low oxidation stability increases the acid value (Carrero and Perez, 2012). The oxidation stability can be improved by 


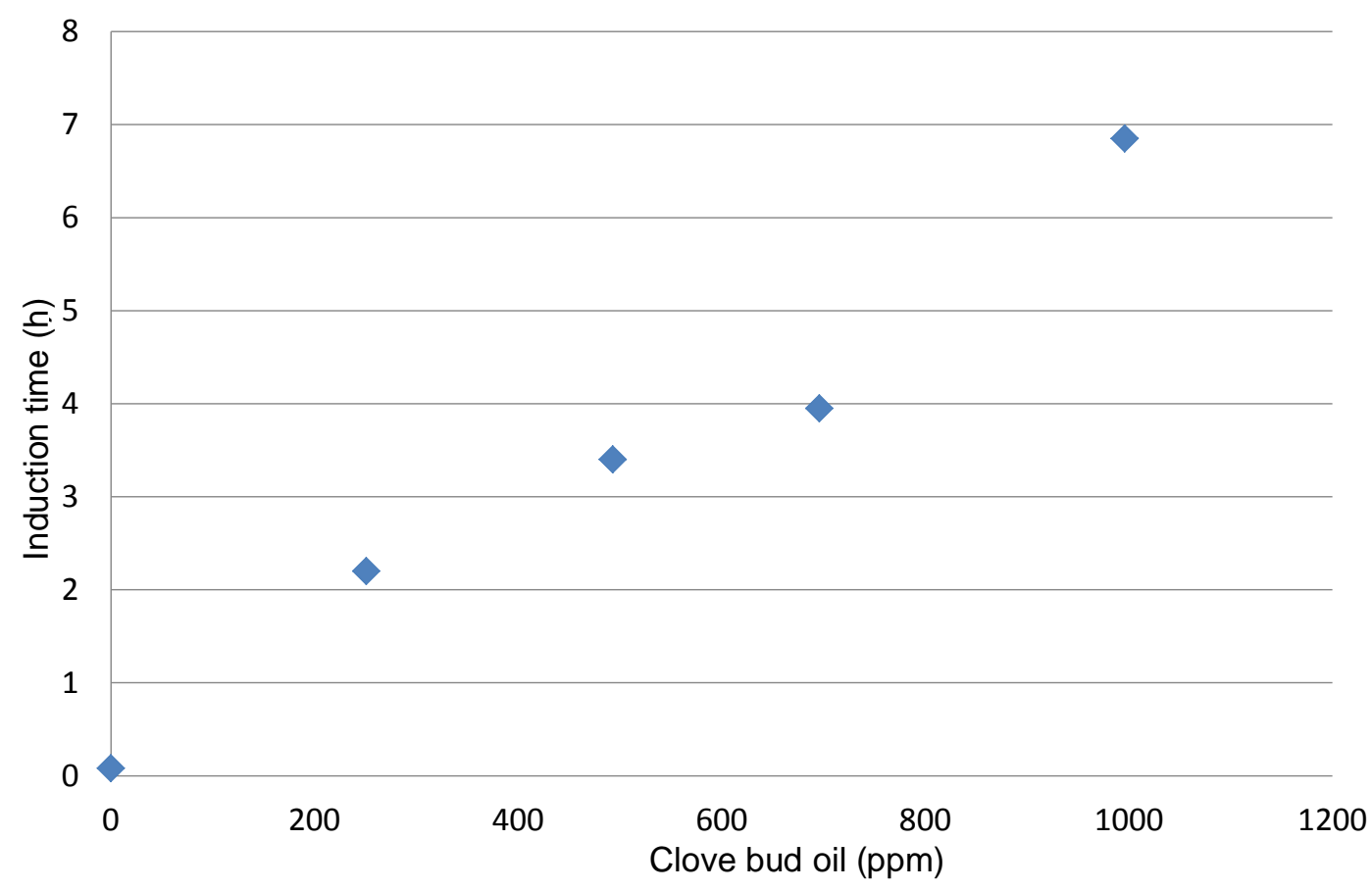

Figure 6. The effect of clove bud oil concentration on the oxidation stability.

the addition of antioxidants or by blending with mineral diesel, which contains antioxidants. A biodiesel/diesel blend of up to 40 vol\% can be used to improve the oxidation stability. The use of commercial antioxidants increases the production cost of biodiesel. The essential oil with the highest anti-oxidative properties is clove bud oil (Teixeira et al., 2013). The effect of different clove bud oil concentrations on the oxidative stability is presented in Figure 6 . The addition of a $1,000 \mathrm{ppm}$ of clove bud oil improved the oxidative stability to meet the SANS 1935:2011 requirements. A very inexpensive essential oil can be used as an antioxidant.

\section{Free and total glycerol}

The use of dry washing resins like Magnesol ${ }^{\circledR} \mathrm{D}-\mathrm{SOL}^{\mathrm{TM}}$ and Purolite ${ }^{\circledR}$ PD-206 can decrease the glycerol content of the biodiesel (Berrios and Skelton, 2008). This is due to the ability of the resins to remove free glycerol and glycerides. The free glycerol content of the biodiesel was reduced from 0.145 to $0.04 \mathrm{wt} \%$ with $1.0 \mathrm{wt} \%$ Magnesol $^{\circledR}$ $\mathrm{D}-\mathrm{SOL}^{\mathrm{TM}}$ in $30 \mathrm{~min}$ and the total glycerol content was reduced from 0.87 to $0.27 \mathrm{wt} \%$. This is still not within the specifications of SANS 1935:2011, but can be reduced with further purification.

\section{Cold filter plugging point}

The cold filter plugging point (CFPP) is a temperature similar to the melting point of the biodiesel. The CFPP is determined by cooling the biodiesel until it is unable to flow through a filter within a specified time. This parameter determines the environmental conditions that the biodiesel can be used in. A biodiesel that does not meet the CFPP requirements will block fuel filters and pipelines (Carrero and Perez, 2012). The specific ester concentration is responsible for this parameter. An increase in unsaturated esters decreases the CFPP, while an increase in chain length of esters increases the CFPP. The ester composition and degree of unsaturation is a major factor in the CFPP. The biodiesel can be blended with mineral diesel in order to reduce the CFPP. The CFPP was reduced from 8 to -5 and $-9^{\circ} \mathrm{C}$ with a biodiesel/diesel blend of $\mathrm{B} 20$ and $\mathrm{B} 10$, respectively, which is well within the range of SANS 1935:2011 and 342:2006.

\section{Conclusions}

The butter waste was subjected to various methods in order to determine its use as a feedstock for biodiesel production. The transesterification reaction was used to produce biodiesel with $96 \mathrm{wt} \%$ ester content. The use of dry washing agents has the ability to reduce the amount of waste produced at a biodiesel plant. Small amounts of the resins or adsorbents are needed to remove impurities from the biodiesel and can be regenerated. The pure biodiesel does not meet the full range of specifications (flashpoint, sulphur content, carbon residue, oxidation 
stability, free and total glycerol, cold filter plugging point), but blending with mineral diesel (B10 or B20) results in an on-specification final product.

\section{REFERENCES}

Berrios M, Skelton RL (2008). Comparison of purification methods for biodiesel. Chem. Eng. J. (Amsterdam, Neth.) 144: 459-465.

Boog JHF, Silveira ELC, de Caland LB, Tudino M (2011). Determining the residual alcohol in biodiesel through its flash point. Fuel 90: 905907.

BP (2012). BP energy outlook 2030 summary tables. [cited 2012 Aug 7] Available http://www.bp.com/liveassets/bp internet/globalbp/STAGING/global assets/downloads/O/2012_BP-Energy-Outlook-2030-summarytables.xls

Carrero A, Perez A (2012). Advances in biodiesel quality, characterisation and standards development. In: Luque KS, Melero JA (2012). Advances in biodiesel production: processes and technologies. Oxford: Woodhead Publishing.

Cvengros J, Cvengrosova Z (2004). Used frying oils and fats and their utilization in the production of methyl esters of higher fatty acids. Biomass Bioenergy 27:173-181.

Ewing M, Msangi S (2009). Biofuels production in developing countries: assessing tradeoffs in welfare and food security. Environ. Sci. Policy 12: 520-528.

Faccini CS, Da Cunha ME, Moraes MSA, Krause LC, Manique MC, Rodrigues MRA, Benvenutti EV, Caramao EB (2011). Dry washing in biodiesel purification, a comparative study of adsorbents. J. Braz. Chem. Soc. 22:558-563.

Hayyan A, Alam MZ, Mirghani MES, Kabbashi NA, Hakimi NINM, Siran YM, Tahiruddin S (2011). Reduction of high content free fatty acid in sludge palm oil via acid catalyst biodiesel production. Fuel Process. Technol. 92:920-924.

Kumar R, Tiwari P, Garg S (2013). Alkali transesterification of linseed oil for biodiesel production. Fuel 104:553-560.
Manique MC, Faccini CS, Onorevoli B, Benvenutti EV, Caramao EB (2012). Rice husk ash as an adsorbent for purifying biodiesel from waste frying oil. Fuel 92:56-61.

Meher LC, Sagar DV, Naik SN (2006). Technical aspects of biodiesel production by transesterification - a review. Renew. Sustain. Energy Rev. 10:248-268.

Pereira MG, Mudge SM, Latchford J (2003). Vegetable oil spills on salt marsh sediments; comparison between sunflower and linseed oils. Mar. Environ. Res. 56:367-385.

SABS (South African Bureau of Standards) (2006). Automotive diesel fuel. Pretoria: SABS, Standards South Africa. (SANS 342:2006).

SABS (South African Bureau of Standards) (2011). Automotive biodiesel, fatty acid methyl esters (FAME) for diesel engines, requirements and test methods. Pretoria: SABS, Standards South Africa. (SANS1935:2011).

Teixeira B, Marques A, Ramos C, Neng NR, Nogueira JMF, Saraiva JA, Nunes ML (2013). Chemical composition and antibacterial and antioxidant properties of commercial essential oils. Ind. Crops Prod. 43:587-595.

United Nations (2011). Department of Economic and Social Affairs. Population Division. Total population (both sexes combined) by major area, region and country, annually for 1950-2100 (thousands). [cited 2012 Sep 9] Available from: http://esa.un.org/wpp/ExcelData/DB02_Stock_Indicators/ WPP2010_DB2_ F01 _TOTAL_ POPULATION_BOTH_SEXES.XLS.

Van Gerpen J (2005). Biodiesel processing and production. Fuel Process. Technol. 86:1097-1107. 